\title{
The Relationship between Intracellular Free Iron and Cell Injury in Cultured Neurons, Astrocytes, and Oligodendrocytes
}

\author{
Geraldine J. Kress, Kirk E. Dineley, and lan J. Reynolds \\ Department of Pharmacology, University of Pittsburgh, Pittsburgh, Pennsylvania 15261
}

Iron is an essential element for cells but may also be an important cytotoxin. However, very little is known about iron transport, redox status, or toxicity specifically inside cells. In this study, we exploited the sensitivity of fura-2 to quenching by ferrous iron $\left(\mathrm{Fe}^{2+}\right)$ to detect intracellular free iron $\left(\left[\mathrm{Fe}^{2+}\right]_{\mathrm{i}}\right)$ in neurons, astrocytes, and oligodendrocytes in primary culture. All cell types exposed to $\mathrm{Fe}^{2+}$ in the presence of the ionophore pyrithione rapidly accumulated $\mathrm{Fe}^{2+}$ to a similar extent. The heavy-metal chelators bipyridyl and $N, N, N^{\prime}, N^{\prime}$-tetrakis(2pyridalmethyl)ethyl-enediamine rapidly reversed the increase in $\left[\mathrm{Fe}^{2+}\right]_{i}$, whereas desferrioxamine had little effect. Interestingly, the $\mathrm{Fe}^{2+}$-mediated quenching of fura-2 fluorescence was reversed in a concentration-dependent manner by hydrogen per- oxide. This was likely caused by the oxidation of $\mathrm{Fe}^{2+}$ to $\mathrm{Fe}^{3+}$ inside the cell. Acute exposure of cells to $\mathrm{Fe}^{2+}$ was only toxic when the metal was applied together with pyrithione, showing that $\mathrm{Fe}^{2+}$ is only toxic when elevated inside cells. Interestingly, only neurons and oligodendrocytes were injured by this elevation in $\left[\mathrm{Fe}^{2+}\right]_{i}$, whereas astrocytes were unaffected, although $\left[\mathrm{Fe}^{2+}\right]_{i}$ was elevated to the same degree in each cell type. These studies provide a novel approach for detecting $\left[\mathrm{Fe}^{2+}\right]_{\mathrm{i}}$ in a manner sensitive to the redox state of the metal. These studies also provide a model system for the study of the toxic consequences of elevated $\left[\mathrm{Fe}^{2+}\right]_{\mathrm{i}}$ in neural cells.

Key words: intracellular iron; fura-2; fluorescent dye; neuron; astrocyte; oligodendrocyte
Iron is an essential element in mammalian cells. However, in common with most multivalent cations, an excess of iron is often toxic, so that a balance between the accumulation of iron, its sequestration within cellular compartments, and its release is essential for the maintenance of cell viability. There are numerous examples of circumstances where this balance is believed to be disrupted in association with damage to the CNS (Gerlach et al., 1994; Connor, 1997; Thompson et al., 2001); e.g., the iron content of nigral Lewy bodies is elevated in patients with Parkinson's disease (Sofic et al., 1988; Dexter et al., 1989; Jellinger, 1999; Kienzl et al., 1999; Castellani et al., 2000). Several studies have reported an increase in cytochemically identifiable iron in association with plaques in Alzheimer's disease (Connor et al., 1992; Good et al., 1992; Deibel et al., 1996; LeVine, 1997; Smith et al., 2000; Thompson et al., 2001), and the primary deficit in Friedrich's ataxia is a limitation of mitochondrial iron efflux (Schapira, 1999; Waldvogel et al., 1999). A disruption of cellular iron handling may also be an important factor in more acute neuronal injury states, because cerebral ischemia has also been associated with an increase in intracellular free iron (Bralet et al., 1992; Aisen, 1994; Lipscomb et al., 1998).

The elevation of free iron represents a potential liability to cells because of the participation of iron in the metabolism of reactive oxygen species (ROS). In particular, ferrous iron $\left(\mathrm{Fe}^{2+}\right)$ has the potential for a catalytic reaction with hydrogen peroxide to generate hydroxyl radical, which is believed to be the most reactive and dangerous form of ROS encountered within cells (Youdim et

Received Jan. 17, 2002; revised March 27, 2002; accepted April 30, 2002.

This work was supported by National Institutes of Health Grant NS 34138 (I.J.R.). We thank Dr. Yong Yun Han for helpful discussion throughout these experiments and Dr. Teresa Hastings for reading this manuscript.

Correspondence should be addressed to Ian J. Reynolds, Department of Pharmacology, University of Pittsburgh, W1351 Biomedical Science Tower, Pittsburgh, PA 15261. E-mail: iannmda@pitt.edu.

Copyright (C) 2002 Society for Neuroscience $\quad 0270-6474 / 02 / 225848-08 \$ 15.00 / 0$ al., 1990; for review, see Lauffer, 1992; Reif, 1992; Winterbourn, 1995; Wardman and Candeias, 1996). Given the ample supply of peroxide by brain mitochondria (Votyakova and Reynolds, 2001), the availability of $\mathrm{Fe}^{2+}$, rather than the oxidized ferric iron $\left(\mathrm{Fe}^{3+}\right)$, may be a key determinant of cell fate.

Although the importance, as well as the potential liability, of iron is well appreciated, the cellular dynamics of iron homeostasis are not well understood. The histochemical study of postmortem samples provides insight into the location of iron deposits but does not address iron movement in relation to the putative injury process. Indeed, based on the currently available body of data, it is even difficult to ascertain whether the site of iron-induced injury is intracellular or extracellular. In the present study, we have adapted the use of a fluorescent dye, fura-2, for the detection of intracellular free iron $\left(\left[\mathrm{Fe}^{2+}\right]_{\mathrm{i}}\right)$. Although this dye is classically considered to be a $\left[\mathrm{Ca}^{2+}\right]_{\mathrm{i}}$ indicator, its sensitivity to transition metals has long been recognized (Grynkiewicz et al., 1985). In combination with an iron-permissive ionophore, we have been able to demonstrate acute increases in $\left[\mathrm{Fe}^{2+}\right]_{i}$ in cultured neurons, astrocytes, and oligodendrocytes. This approach also permits the determination of the effectiveness of extracellularly applied iron chelators in reducing $\left[\mathrm{Fe}^{2+}\right]_{\mathrm{i}}$ concentrations and can also be used to demonstrate the redox conversion of iron from $\mathrm{Fe}^{2+}$ to $\mathrm{Fe}^{3+}$ and its spontaneous re-reduction in intact cells. Remarkably, although the transient elevations in $\left[\mathrm{Fe}^{2+}\right]_{\mathrm{i}}$ are toxic to both neurons and oligodendrocytes, astrocytes appear to be relatively insensitive to iron-induced cellular injury. Some of these findings have been presented previously in abstract form (Kress et al., 2000).

\section{MATERIALS AND METHODS}

Reagents and solutions. All imaging and toxicity reagents were purchased from Sigma (St. Louis, MO) unless otherwise noted. All culture reagents were purchased from Invitrogen (Carlsbad, CA) unless otherwise noted. During imaging experiments, coverslips were continuously superfused 
with Tris-buffered salt solution (TBSS), which contained (in mM): 140 $\mathrm{NaCl}, 5 \mathrm{KCl}, 0.9 \mathrm{MgSO}_{4}, 10 \mathrm{NaHCO}_{3}, 20$ Tris, and 5.5 glucose, adjusted to $\mathrm{pH}$ 7.4. When desired, $\mathrm{Fe}^{2+}, \mathrm{Fe}^{3+}$, or $\mathrm{Zn}^{2+}$ was added to the buffer from a $1000 \times$ stock of $\mathrm{FeCl}_{2}, \mathrm{FeCl}_{3}$, or $\mathrm{ZnCl}_{2}$. The zinc- and ironspecific ionophore, sodium 1-hydroxypyridine-2-thione, also known as sodium pyrithione (Pyr), was added at a concentration of $20 \mu \mathrm{M}$ from a $20 \mathrm{~mm}$ stock dissolved in DMSO. The chelators 2,2' -bipyridine [150 $\mu \mathrm{M}$ bipyridyl (BIP)], deferoxamine mesylate [75 or $150 \mu \mathrm{M}$ desferrioxamine (DFO)], $25 \mu \mathrm{M} N, N, N^{\prime}, N^{\prime}$-tetrakis(2-pyridalmethyl)ethyl-enediamine (TPEN), and $10 \mu \mathrm{M}$ 1,10-phenanthroline (Phen) were added from a $1000 \times$ stock in DMSO, water, DMSO, and absolute ethanol, respectively. To reduce trace metals, $20 \mu \mathrm{M}$ EDTA was added to TBSS from a $20 \mathrm{~mm}$ aqueous stock at $\mathrm{pH}$ 7.4.

Neuronal cell culture. Primary cultures of embryonic rat forebrain neurons for fluorescence experiments were prepared as described previously (Brocard et al., 2001). Briefly, embryonic day 17 Sprague Dawley rat fetuses were surgically removed from an anesthetized dam. The forebrains were then dissected from the fetus, dissociated by trypsinization, and plated onto poly-D-lysine (PDL)-coated $31 \mathrm{~mm}$ glass coverslips in DMEM, supplemented with $10 \%$ fetal bovine serum (FBS), penicillin $\left(100 \mathrm{U} \mathrm{ml}^{-1}\right)$, and streptomycin $\left(100 \mu \mathrm{g} \mathrm{ml}^{-1}\right)$. Twenty-four hours after plating, the medium was replaced with medium containing $10 \%$ donor horse serum in place of FBS, and the coverslips were inverted to inhibit proliferation of non-neuronal cells. All imaging experiments were performed on neurons maintained for $12-16 \mathrm{~d}$ in vitro (DIV) in a humidified incubator flushed with $95 \%$ air and $5 \% \mathrm{CO}_{2}$. For toxicity experiments, primary cultures of embryonic rat forebrain neuron experiments were prepared as follows. As described above, the forebrains were collected from embryonic day 17 rat fetuses, dissociated by trypsinization, and plated onto PDL-coated 12 and $31 \mathrm{~mm}$ glass coverslips in DMEM, 10\% FBS, penicillin $\left(100 \mathrm{U} \mathrm{ml}^{-1}\right)$, and streptomycin $\left(100 \mu \mathrm{g} \mathrm{ml}^{-1}\right)$. Five hours after plating, the medium was replaced with neurobasal medium $(\mathrm{NM}), \mathrm{N} 2$ supplement $(1 \times)$, and antibiotics. After 5 DIV, one-third of the medium was changed with NM and N2 supplement. After 9 DIV, one-third of the medium was changed with NM, B27 supplement $(1 \times)$, and antibiotics. All toxicity experiments were performed on neurons at 12-16 DIV.

Type I astrocyte and oligodendrocyte cell culture. Primary cultures of type I astrocytes and oligodendrocytes were prepared as described previously (McCarthy and de Vellis, 1980; Golub et al., 1996). Briefly, cortices from postnatal day 1-4 Sprague Dawley rat pups were dissociated by trypsinization and plated on $75 \mathrm{~mm}^{2}$ flasks in glial medium [basal Eagle's medium, $15 \%$ FBS, $0.1 \%$ glutamine, $0.6 \%$ glucose, penicillin (100 $\mathrm{U} \mathrm{ml}^{-1}$ ), and streptomycin $\left.\left(100 \mu \mathrm{g} \mathrm{ml}^{-1}\right)\right]$. Ten days after plating (the medium was changed every other day), the flasks were shaken at $200 \mathrm{rpm}$ for $4 \mathrm{hr}$ at $37^{\circ} \mathrm{C}$ to remove microglia, the medium was replaced and incubated for $4 \mathrm{hr}$, and then the flasks were shaken again at $200 \mathrm{rpm}$ for $16 \mathrm{hr}$. After shaking, the flask-adherent cells were predominantly type I astrocytes, whereas the supernatant was composed of oligodendrocytes and microglia. The predominantly oligodendrocyte and microglialcontaining supernatant was plated onto $75 \mathrm{~mm}^{2}$ flasks and returned to the incubator in oligodendrocyte media (MEM with $10 \%$ fetal bovine serum, $0.6 \%$ glucose, $50 \mathrm{U} / \mathrm{ml}$ penicillin, and $50 \mathrm{U} / \mathrm{ml}$ streptomycin). After 1-2 hr of adhesion, vigorous shaking of flasks by hand loosened poorly adhered oligodendrocytes. The supernatant was collected and then plated onto PDL-coated glass coverslips establishing an oligodendrocyte culture. The flask-adherent type I astrocytes were trypsinized and plated onto PDL-coated glass coverslips in glial medium. All astrocyte and oligodendrocyte experiments were performed 2-6 d after plating on coverslips. All procedures using animals were in accordance with the National Institutes of Health Guide for the Care and Use of Laboratory Animals and approved by the Institutional Animal Care and Use Committee of the University of Pittsburgh.

Cuvette-based fluorescence measurements. In a cell-free system, the interaction between fura- 2 and $\mathrm{Fe}^{2+}, \mathrm{Fe}^{3+}$, and $\mathrm{Zn}^{2+}$ was measured using a Shimadzu (Kyoto, Japan) RF-5301 spectrofluorimeter with stirrer at room temperature. A $100 \mathrm{~nm}$ concentration of fura-2 pentapotassium salt (Molecular Probes, Eugene, OR) was added to a solution of 20 $\mathrm{mm}$ Tris and $125 \mathrm{~mm}$ potassium chloride in a quartz cuvette. The metal chelators EDTA $(20 \mu \mathrm{M})$ or phenanthroline $(10 \mu \mathrm{M})$ were used to buffer the free ion concentration. The dissociation constants of phenanthroline for $\mathrm{Fe}^{2+}, \mathrm{Fe}^{3+}$, and $\mathrm{Zn}^{2+}$ are 5.86, 6.5, and 6.55, respectively, whereas for EDTA, these values are 14.3, 25.1, and 16.7 (SC-Database; Academic Software, Harrogate, UK). After an addition of $\mathrm{Fe}^{2+}, \mathrm{Fe}^{3+}$, or $\mathrm{Zn}^{2+}$ solution, an excitation spectrum was obtained with wavelengths from 300 to $500 \mathrm{~nm}$, using a $510 \mathrm{~nm}$ emission wavelength. To determine the ion to dye binding affinity, data were fit to a sigmoidal dose-response (variable slope) model using Prism 3.0 (GraphPad Software, Inc., San Diego, CA). The free ion concentration after each addition was calculated with $\mathrm{EqCal}$ (Elsevier Biosoft, Ferguson, MO).

Fluorescence microscopy. For measurement of $\left[\mathrm{Fe}^{2+}\right]_{\mathrm{i}}$, cells were loaded with fura-2 AM (Molecular Probes) by incubating coverslips in the dark at $37^{\circ} \mathrm{C}$ for $15 \mathrm{~min}$ in $1 \mathrm{ml}$ of TBSS containing $5 \mu \mathrm{M}$ fura-2 AM and $0.05 \%$ DMSO. Because astrocytes occasionally showed punctuate labeling indicative of dye compartmentalization, dye loading was done at room temperature (Tsien, 1999). After loading, coverslips were mounted in a recording chamber and superfused with TBSS with $20 \mu \mathrm{M}$ EDTA at $10 \mathrm{ml} \mathrm{min}{ }^{-1}$. The personal computer-based imaging system used in these experiments consisted of the following components: a Nikon (Tokyo, Japan) Diaphot 300 microscope equipped with a $40 \times$ oil immersion objective, a CCD camera (Hamamatsu Photonics, Hamamatsu City, Japan), a software package (SimpePCI; Compix, Cranberry, PA), and a monochromator-driven xenon light source (ASI, Eugene, OR) as described previously (Dineley et al., 2000). Cells were alternately illuminated at 340 and $375 \mathrm{~nm}$, and the emitted light was passed through a 400 $\mathrm{nm}$ dichroic and a 510/80 $\mathrm{nm}$ wideband emission filter before detection by the camera. Background fluorescence values were recorded from cellfree area and subtracted from respective signals. Fluorescence units are expressed as arbitrary fluorescence units. No attempt was made to convert the fura- 2 intensity values to $\left[\mathrm{Fe}^{2+}\right]_{\mathrm{i}}$ or $\left[\mathrm{Zn}^{2+}\right]_{\mathrm{i}}$. All recordings were performed at room temperature.

$\left[\mathrm{Fe}^{2+}\right]_{i}$ toxicity. For toxicity experiments, $12 \mathrm{~mm}$ coverslips of neurons, oligodendrocytes, and astrocytes were washed four times with TBSS and placed into a new culture well. A 75 or $150 \mu \mathrm{M}$ concentration of $\mathrm{FeCl}_{2}$ with or without $75 \mu \mathrm{M}$ DFO and/or $20 \mu \mathrm{M}$ Pyr was added to TBSS containing $20 \mu \mathrm{M}$ EDTA, and $1 \mathrm{ml}$ of this solution was applied to coverslips for $5 \mathrm{~min}$ at room temperature. Washing four times with excess TBSS terminated stimuli. Coverslips were then transferred to a new culture well containing MEM and returned to the incubator. After $8 \mathrm{hr}$, the supernatant was collected and assayed for lactate dehydrogenase (LDH) released into the medium using a cytotoxicity detection kit (1644793; Roche, Hertforshire, UK) and a spectrophotometer wavelength absorbance at $490 \mathrm{~nm}$. Results were normalized to $100 \% \mathrm{LDH}$ release and determined by exposing cells to the calcium ionophore $10 \mu \mathrm{M}$ 4-bromo-A23187 in MEM for $8 \mathrm{hr}$.

Data analysis. Statistical significance was tested using one-way ANOVA, and post-test analyzes were performed using the Bonferroni method as calculated by Prism 3.0 (GraphPad Software, Inc., San Diego, CA).

\section{RESULTS}

\section{Iron sensitivity of fura-2}

Fura-2 is widely used as an indicator of intracellular-free calcium $\left(\left[\mathrm{Ca}^{2+}\right]_{\mathrm{i}}\right)$, but early studies established its sensitivity to other ions (Grynkiewicz et al., 1985); e.g., fura-2 is very sensitive to $\mathrm{Zn}^{2+}$ and can be used to monitor small changes in $\left[\mathrm{Zn}^{2+}\right]_{i}$ in neurons (Cheng and Reynolds, 1998). Cations, such as $\mathrm{Ca}^{2+}$ and $\mathrm{Zn}^{2+}$, alter the excitation spectrum of fura- 2 and shift the peak excitation wavelength from $\sim 365$ to $\sim 340 \mathrm{~nm}$, which provides the basis for ratiometric imaging approaches (Fig. $1 A$ ). A number of other heavy metals produce a concentration-dependent quenching of the fura-2 signal without altering the position of the excitation spectrum. Both $\mathrm{Fe}^{2+}$ (Fig. $1 A$ ) and $\mathrm{Fe}^{3+}$ (data not shown) have this property. Thus, by monitoring quenching rather than the shift in excitation peak, it is possible to distinguish between $\mathrm{Ca}^{2+}$ - and $\mathrm{Zn}^{2+}$-like effects compared with $\mathrm{Fe}^{2+}$-like effects.

Because there is relatively little information available about the sensitivity of fura-2 to quenching by $\mathrm{Fe}^{2+}$ and $\mathrm{Fe}^{3+}$, we first evaluated the sensitivity of the dye in vitro (Fig. $1 B$ ). $\mathrm{Fe}^{2+}$ had a high affinity for fura-2 $(5.03 \pm 0.86 \mathrm{nM})$, whereas $\mathrm{Fe}^{3+}$ had $\sim 1000$-fold lower affinity than $\mathrm{Fe}^{2+}(7.34 \pm 1.17 \mu \mathrm{M})$, indicating that fura-2 should preferentially bind to ferrous iron. Shown for comparison is the effect of $\mathrm{Zn}^{2+}(15.5 \pm 0.44 \mathrm{nM})$, which increased the fluorescence emission at an excitation wavelength of $340 \mathrm{~nm}$, consistent with its ability to shift the excitation spectrum. 

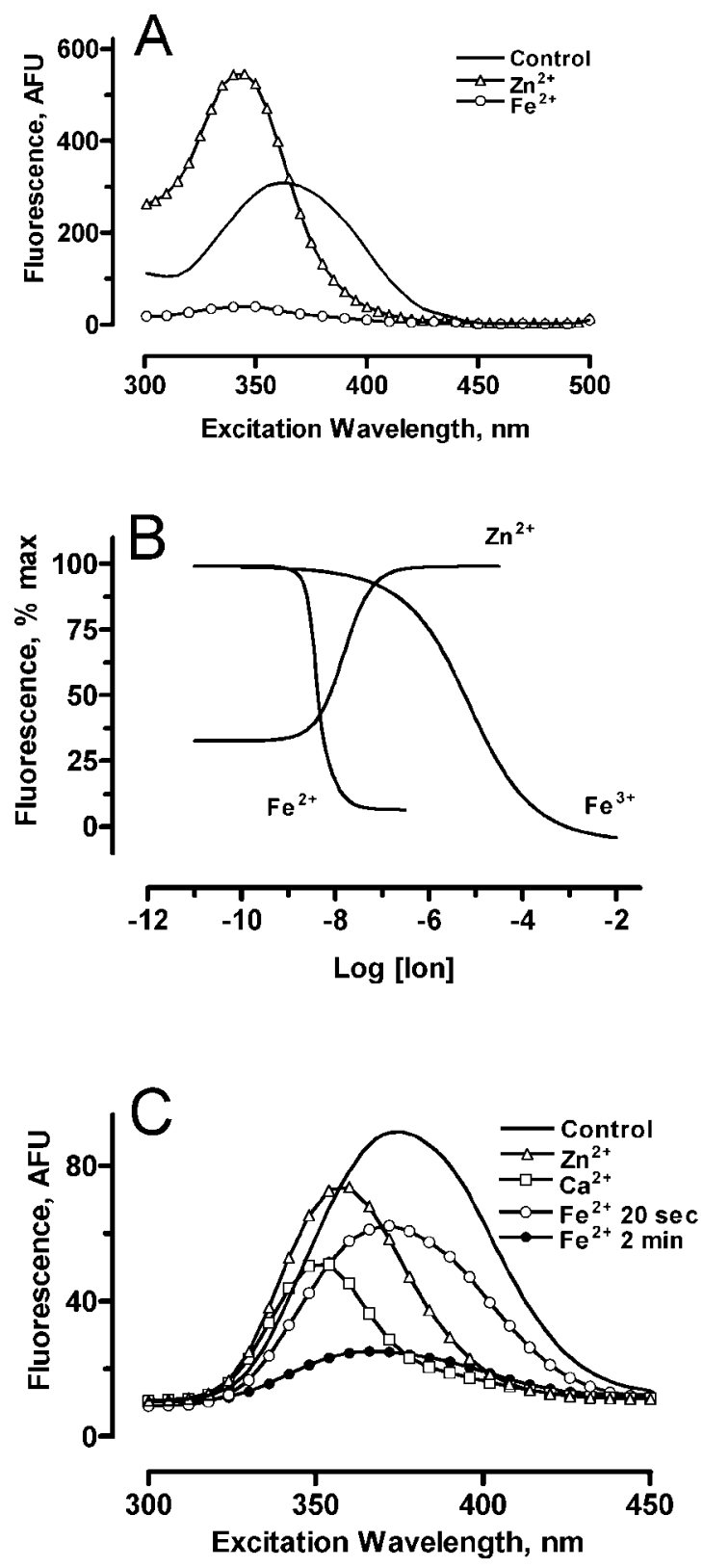

Figure 1. Interaction between $\mathrm{Fe}^{2+}$ and fura-2 in vitro. $A$, Spectra of fura-2 were obtained in the absence or presence of saturating concentrations of $\mathrm{Fe}^{2+}$ or $\mathrm{Zn}^{2+}$ as indicated. Fluorescence emission was measured at $510 \mathrm{~nm}$. Note that $\mathrm{Fe}^{2+}$ results in quenching of the fura-2 signal at all wavelengths, which is in contrast to the spectral shift evident with $\mathrm{Zn}^{2+}$. $B$, The effects of $\mathrm{Fe}^{2+}, \mathrm{Fe}^{3+}$, or $\mathrm{Zn}^{2+}$ were determined by monitoring fura-2 fluorescence emission intensity at an excitation wavelength of 340 $\mathrm{nm}$. The signal was measured after additions of $\mathrm{Fe}^{2+}, \mathrm{Fe}^{3+}$, or $\mathrm{Zn}^{2+}$ and normalized to values obtained before the addition of ions. Fura- 2 measurements were made of desired ion in the presence of $10 \mu \mathrm{M}$ phenanthroline and are presented as free ion concentrations. The calculated $\mathrm{EC}_{50}$ values of fura- 2 for $\mathrm{Fe}^{2+}, \mathrm{Fe}^{3+}$, and $\mathrm{Zn}^{2+}$ are $5.03 \pm 0.86 \mathrm{nM}, 7.34 \pm 1.17$ $\mu \mathrm{M}$, and $15.5 \pm 0.44 \mathrm{nM}$, respectively (mean \pm SEM of at least three independent experiments per ion). $C$, Spectral properties of fura-2 inside neurons. Fura-2-loaded neurons were perfused with TBSS and stimulated for $5 \mathrm{~min}$ with either $30 \mu \mathrm{M} \mathrm{Zn^{2+ }} / 20 \mu \mathrm{M}$ pyrithione (saturating $\mathrm{Zn}^{2+}, \triangle$ ), $100 \mu \mathrm{M}$ glutamate $/ 10 \mu \mathrm{M}$ glycine in the presence of $1.4 \mathrm{mM}$ extracellular $\mathrm{Ca}^{2+}$ (saturating $\mathrm{Ca}^{2+}, \square$ ), or $150 \mu \mathrm{M} \mathrm{Fe}{ }^{2+} / 75 \mu \mathrm{M} \mathrm{DFO} / 20 \mu \mathrm{M}$ Pyr for $30 \mathrm{sec}(\bigcirc)$ or $2 \mathrm{~min}(\bullet)$. The spectra were obtained by scanning the excitation wavelength from 300 to $450 \mathrm{~nm}$ and determining the emission wavelength intensity. The trace without symbols represents the initial fura-2 intensity of TBSS-perfused neurons. $A F U$, Arbitrary fluorescence units.
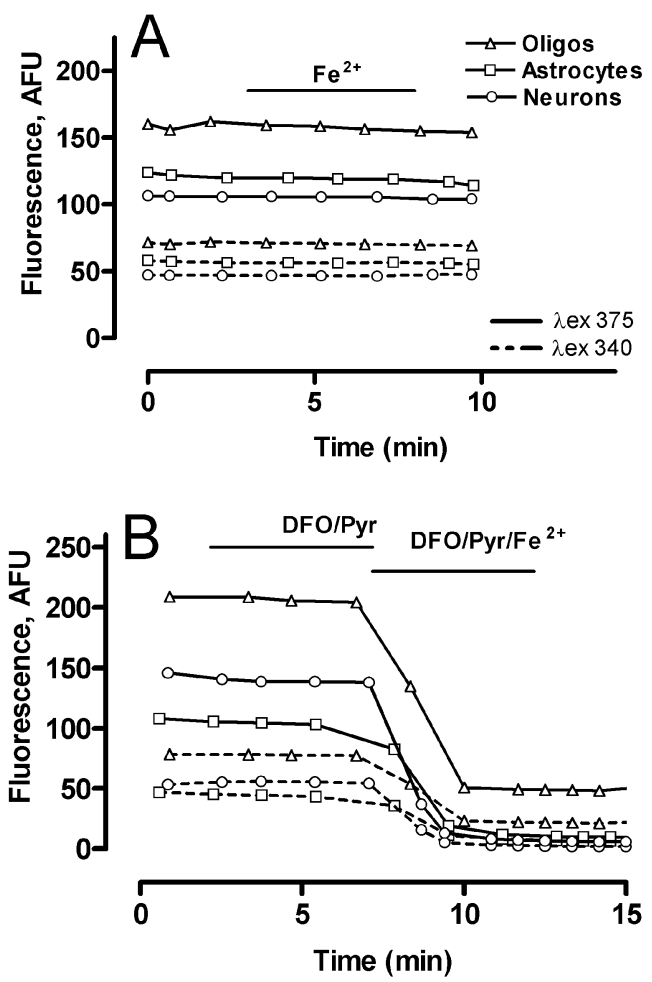

Figure 2. Pyrithione facilitates $\mathrm{Fe}^{2+}$ influx into neurons, astrocytes, and oligodendrocytes (Oligos). Cells were loaded with $5 \mu \mathrm{M}$ fura-2, perfused with TBSS, and exposed to $150 \mu \mathrm{M} \mathrm{Fe}{ }^{2+} / 150 \mu \mathrm{M}$ DFO for 5 min $(A)$ or $20 \mu \mathrm{M} \mathrm{Pyr} / 75 \mu \mathrm{M}$ DFO (B), followed by $20 \mu \mathrm{M} \mathrm{Pyr} / 75 \mu \mathrm{M}$ DFO/150 $\mu \mathrm{M}$ $\mathrm{Fe}^{2+}$. The fluorescence intensity after fura-2 excitation at $375 \mathrm{~nm}(\lambda e x)$ is represented by a solid line, and the fluorescence intensity after fura-2 excitation at $340 \mathrm{~nm}$ is indicated by a dashed line. The decrease in signal at both wavelengths is inconsistent with the fluorescence change being a consequence of either intracellular calcium or zinc changes. Each trace represents the average intensity of all cells from a single coverslip, and each condition was repeated at least three more times with similar results. $A F U$, Arbitrary fluorescence units.

The in vitro spectra obtained with ultraviolet dyes, such as fura-2, differ somewhat from that obtained in dye-loaded neurons (Fig. $1 C)$. Notably, the prominent peak that is evident at shorter wavelengths is not evident, which presumably is a reflection of the relatively poor penetration of short-wavelength light through the microscope optics. Nevertheless, the important distinction is that $\mathrm{Ca}^{2+}$ and $\mathrm{Zn}^{2+}$ shift and lower the excitation peak when the dye is inside cells, whereas $\mathrm{Fe}^{2+}$ decreases fluorescence intensity without shifting the peak. Compared with resting conditions (which are dominated by low, physiological $\mathrm{Ca}^{2+}$ concentrations), a substantial elevation of either $\left[\mathrm{Ca}^{2+}\right]_{i}$ or $\left[\mathrm{Zn}^{2+}\right]_{i}$ produces a clear shift in the excitation peak from $\sim 375$ to $\sim 350 \mathrm{~nm}$. In contrast, elevating $\mathrm{Fe}^{2+}$ (using approaches described below) suppresses the fura-2 signal at all wavelengths (Fig. 1C).

\section{Pyrithione transports $\mathrm{Fe}^{2+}$ into cells}

Transiently exposing fura-2-loaded neurons, astrocytes, or oligodendrocytes to $\mathrm{Fe}^{2+}$ does not change the intracellular dye signal (Fig. 2A), suggesting absence of any mechanisms capable of mediating acute iron entry. To effectively study the dynamics of $\left[\mathrm{Fe}^{2+}\right]_{\mathrm{i}}$, a method of elevating $\left[\mathrm{Fe}^{2+}\right]_{\mathrm{i}}$ was necessary. We have previously used sodium pyrithione to transport $\mathrm{Zn}^{2+}$ into both neurons and astrocytes (Dineley et al., 2000) and reasoned that pyrithione might work effectively on $\mathrm{Fe}^{2+}$ as well. However, 
simply adding pyrithione to superfusion buffers often resulted in changes in fura- 2 fluorescence that were presumably caused by low levels of contaminating metals in the buffer solutions together with the sensitivity of fura- 2 to very low concentrations of zinc and possibly iron (data not shown). Note, however, that pyrithione does not support calcium entry into neurons (Dineley et al., 2000). To effectively control the flux of contaminating ions, we applied pyrithione in the presence of $75 \mu \mathrm{M}$ DFO. DFO has a high affinity for $\mathrm{Fe}^{2+}, \mathrm{Fe}^{3+}$, and $\mathrm{Zn}^{2+}(\log K$ values of 7.2, 31, and 11.1, respectively) and should thus maintain these key species at relatively low concentrations.

Adding pyrithione in the presence of DFO produced little change in the fura-2 signal (Fig. $2 B$ ), whereas exposing cells to pyrithione and DFO in the presence of $150 \mu \mathrm{M} \mathrm{FeCl} l_{2}$ produced a prompt decrease in the fluorescence signal that persisted even when the ionophore mixture was removed (Fig. 2B). Adding $\mathrm{DFO}$ and $\mathrm{Fe}^{2+}$ without pyrithione did not alter the fura-2 signal, and the combination of DFO, pyrithione, and an excess of $\mathrm{Fe}^{3+}$ was similarly without effect (data not shown), although it is difficult to be certain under these conditions that pyrithione actually transported the $\mathrm{Fe}^{3+}$ into cells. As illustrated in Figure $1 C$, the combination of DFO, pyrithione, and $30 \mu \mathrm{M} \mathrm{Zn}^{2+}$ produces effects on the fura- 2 signal that are quite distinct from the effects of $\mathrm{Fe}^{2+}$. Thus, we conclude that fura- 2 effectively reports an increase in $\left[\mathrm{Fe}^{2+}\right]_{\mathrm{i}}$.

\section{The effects of iron chelators}

The introduction of $\mathrm{Fe}^{2+}$ into the cytoplasm of neurons results in a sustained decrease in the fura-2 signal (Fig. 3) that was maintained for periods of $>10 \mathrm{~min}$. The essential absence of spontaneous recovery of this signal could reflect the low capacity of iron homeostasis mechanisms within the cell. Nevertheless, this approach of $\mathrm{Fe}^{2+}$ delivery is useful for assessing the effectiveness of putative iron chelators. The most widely used chelator is DFO. DFO had absolutely no effect on the $\left[\mathrm{Fe}^{2+}\right]_{\mathrm{i}}$ signal when acutely applied to neurons (Fig. $3 A$ ). This presumably reflects a lack of cell penetration of this chelator, at least over the time course of these relatively acute experiments. The cell permeant iron chelator BIP (Breuer et al., 1995a) rapidly reversed the $\left[\mathrm{Fe}^{2+}\right]_{\mathrm{i}}$ signal, typically to within $\sim 70-80 \%$ of initial values. The heavymetal chelator TPEN was also very effective in reversing $\left[\mathrm{Fe}^{2+}\right]_{\mathrm{i}}$ changes (Fig. $3 A$ ), in addition to its known effects on $\left[\mathrm{Zn}^{2+}\right]_{\mathrm{i}}$ (Fig. $3 B$ ). Note also that elevation of $\left[\mathrm{Zn}^{2+}\right]_{i}$ results in a decrease in fluorescence emission at $375 \mathrm{~nm}$ but an increase in the emission after illumination at $340 \mathrm{~nm}$ (Fig. $3 B$ ). This is in marked contrast to the effects of elevating $\left[\mathrm{Fe}^{2+}\right]_{\mathrm{i}}$, where the emission at both wavelengths is decreased (Fig. $3 A$ ). These findings illustrate the value of a direct measurement of $\left[\mathrm{Fe}^{2+}\right]_{\mathrm{i}}$ in determining the cellular localization and effectiveness of action of agents that are reported to chelate intracellular cations.

\section{Redox modulation of the $\left[\mathrm{Fe}^{2+}\right]_{\mathrm{i}}$ signal}

The redox state of free iron in cells is an important parameter, because the catalysis of $\mathrm{H}_{2} \mathrm{O}_{2}$ into hydroxyl radical (the Fenton reaction) requires the presence of $\mathrm{Fe}^{2+}$ rather than $\mathrm{Fe}^{3+}$ (for review, see Winterbourn, 1995). The in vitro data (Fig. 1) show that fura-2 preferentially binds $\mathrm{Fe}^{2+}$ over $\mathrm{Fe}^{3+}$, raising the possibility that fura- 2 might effectively report the redox state of the free iron in this system. We examined this possibility using the paradigm shown in Figure $4 A$. We transiently exposed $\mathrm{Fe}^{2+}$ loaded neurons to $\mathrm{H}_{2} \mathrm{O}_{2}$, followed by a washout of the oxidant and then reversal of the $\mathrm{Fe}^{2+}$ signal by TPEN. In contrast, adding
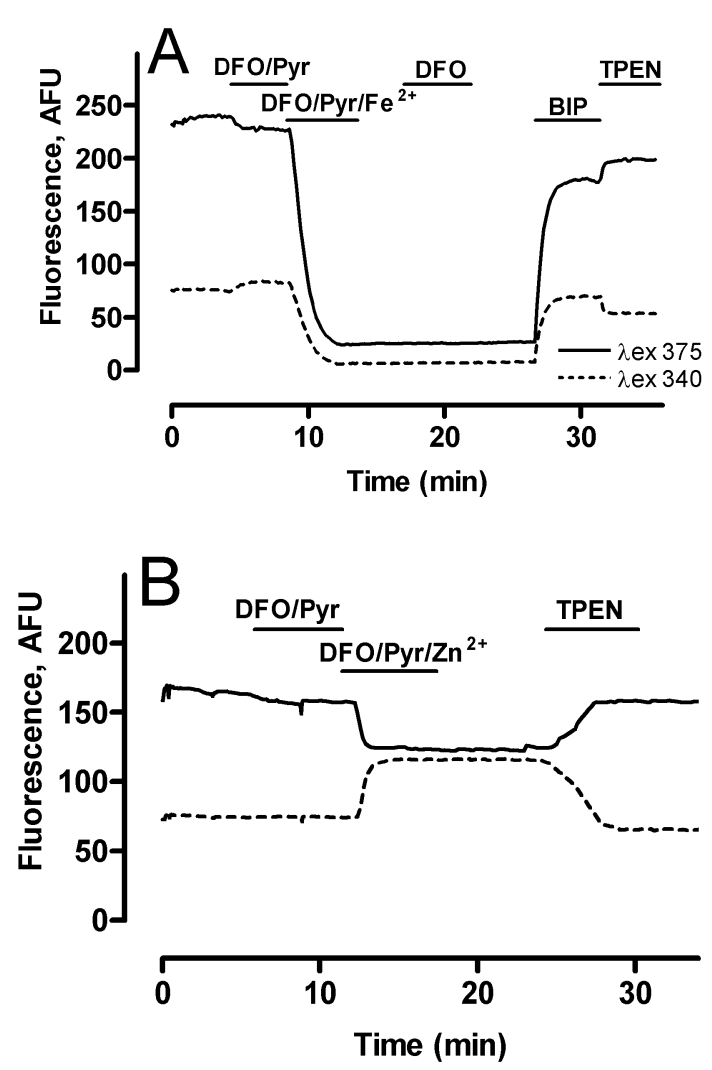

Figure 3. Effects of heavy-metal chelators on the fura-2 signal. A, Cells were perfused with TBSS with the indicated stimuli at previous concentrations. After quenching of fura- 2 with $150 \mu \mathrm{M} \mathrm{Fe}{ }^{2+}$, the following chelators were applied for $5 \mathrm{~min}$ (in $\mu \mathrm{M}$ ): $150 \mathrm{DFO}$, an $\mathrm{Fe}^{3+}$ chelator; 150 $\mathrm{BIP}$, an $\mathrm{Fe}^{2+}$ chelator; and 25 TPEN, a nonselective heavy-metal chelator. $B$, Fura-2-loaded neurons were perfused with TBSS without EDTA and then stimulated for $5 \mathrm{~min}$ with $75 \mu \mathrm{M}$ DFO/20 $\mu \mathrm{M}$ Pyr, followed by 75 $\mu \mathrm{M}$ DFO/20 $\mu \mathrm{M} \mathrm{Pyr} / 30 \mu \mathrm{M} \mathrm{Zn^{2+ }}$ and $25 \mu \mathrm{M}$ TPEN, a divalent metal chelator. Note that after $\mathrm{Zn}^{2+}$ entry, the $375 \mathrm{~nm}$ excitation wavelength intensity decreases and the $340 \mathrm{~nm}$ intensity increases, consistent with $\mathrm{Zn}^{2+}$ entry (or $\mathrm{Ca}^{2+}$; entry not shown) but not of $\mathrm{Fe}^{2+}$ entry. Fura-2 excitation at $375 \mathrm{~nm}$ ( $\lambda$ ex $)$ is represented by a solid line, and fura-2 excitation at $340 \mathrm{~nm}$ is indicated by a dashed line. The traces represent the average intensity of all cells from a single coverslip, and each condition was repeated at least three more times with similar results. $A F U$, Arbitrary fluorescence units.

$\mathrm{H}_{2} \mathrm{O}_{2}$ to a $\mathrm{Zn}^{2+}$-loaded neuron did not alter the fluorescence signal (Fig. $4 B$ ). This suggests that the $\mathrm{H}_{2} \mathrm{O}_{2}$ effect was not the result of oxidation of the dye $\mathrm{H}_{2} \mathrm{O}_{2}$ produced a reversal of the fura-2 quenching that was concentration dependent in all three cell types (Fig. 5). However, the characteristics of the fluorescence changes varied between cell types, and this is established both by the illustrative traces (Fig. $5 A-C$ ) and by the summary graphs (Fig. $5 D-F$ ); e.g., astrocytes appeared to be much more sensitive to $\mathrm{H}_{2} \mathrm{O}_{2}$ than neurons or oligodendrocytes in this assay, because lower concentrations of $\mathrm{H}_{2} \mathrm{O}_{2}$ were required to reverse the fluorescence quenching, and there was relatively little spontaneous recovery after $\mathrm{H}_{2} \mathrm{O}_{2}$ removal (Fig. $5 E$ ) compared with the other cell types. In neurons and oligodendrocytes, the extent of this spontaneous recovery of quenching diminished as the $\mathrm{H}_{2} \mathrm{O}_{2}$ increased. This may reflect the concentrations of $\mathrm{H}_{2} \mathrm{O}_{2}$ that overwhelm the antioxidant capacity of the cells. Overall, these findings are consistent with the $\mathrm{H}_{2} \mathrm{O}_{2}$-mediated oxidation of $\mathrm{Fe}^{2+}$ to $\mathrm{Fe}^{3+}$. This results in a reversal of dye quenching because of the lower affinity of $\mathrm{Fe}^{3+}$ for fura-2 (Fig. 1B). The spontaneous 


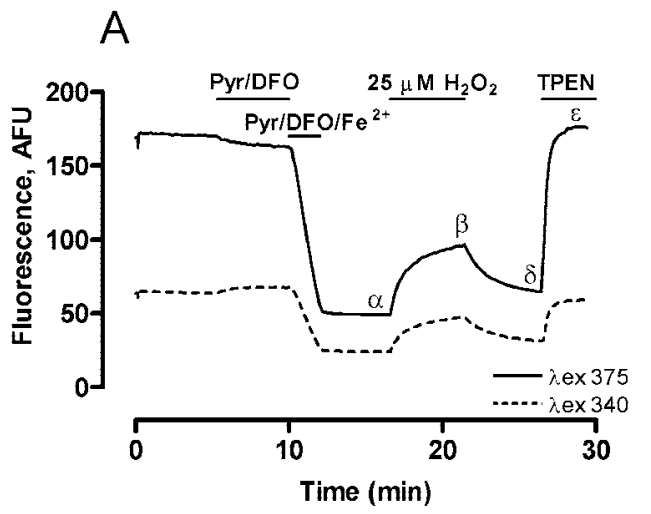

B

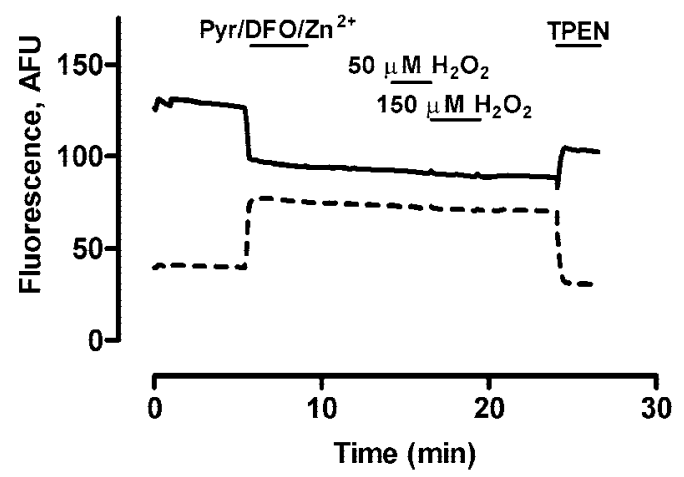

Figure 4. Hydrogen peroxide modulation of $\left[\mathrm{Fe}^{2+}\right]_{\mathrm{i}} . A$, Neurons were perfused with TBSS and exposed to $\mathrm{Fe}^{2+}$ in the presence of pyrithione to elevate $\left[\mathrm{Fe}^{2+}\right]_{\text {. }}$. After washout of the $\mathrm{Fe}^{2+}$ loading stimulus, neurons were transiently exposed to $25 \mu \mathrm{M} \mathrm{H}_{2} \mathrm{O}_{2}$. Removal of the oxidant resulted in the recovery of the quenching effect in this experiment. The fura-2 signal was fully restored by perfusing TPEN over the cells. Fura- 2 excitation at 375 $\mathrm{nm}(\lambda e x)$ is represented by a solid line and fura- 2 excitation at $340 \mathrm{~nm}$ is indicated by a dashed line. $B$, Using a similar approach, fura-2-loaded cells were exposed to $30 \mu \mathrm{M} \mathrm{Zn}{ }^{2+}$ in the presence of pyrithione. After washout of the $\mathrm{Zn}^{2+}$ and pyrithione, $50 \mu \mathrm{M}$ and then $150 \mu \mathrm{M} \mathrm{H} \mathrm{H}_{2} \mathrm{O}_{2}$ was added to the cells as indicated. No alterations in fluorescence emission at either 340 or $380 \mathrm{~nm}$ were observed. The traces represent the average intensity of all cells from a single coverslip, and each condition was repeated at least three more times with similar results. $A F U$, Arbitrary fluorescence units.

reversal of the quenching on peroxide removal is presumably caused by the normal reducing environment of the intracellular milieu, which can be overcome if a sufficient concentration of oxidant is used.

\section{Effects of $\mathrm{Fe}^{2+}$ on cell viability}

Having established that it was possible to acutely deliver $\mathrm{Fe}^{2+}$ to these cells, it was then possible to determine the impact of a brief exposure to $\mathrm{Fe}^{2+}$ on cell viability. In these experiments, we assayed LDH activity as a marker of cell injury and performed this assay $8 \mathrm{hr}$ after a $5 \mathrm{~min}$ exposure to various components of the $\mathrm{Fe}^{2+} / \mathrm{DFO} /$ pyrithione mixture used in Figures 2-5. LDH release was normalized to the signal produced by cells exposed to a $10 \mu \mathrm{M}$ concentration of the calcium ionophore 4-bromo-A23187 as a positive control, which effectively released $\mathrm{LDH}$ in all cell types. As illustrated in Figure $6 A$, exposing neurons to pyrithione alone or with DFO, or exposing neurons to $\mathrm{Fe}^{2+}$ alone, had no effect on viability. The combination of pyrithione and $\mathrm{Fe}^{2+}$ produced substantial toxicity to neurons but only when sufficient $\mathrm{Fe}^{2+}$ was supplied to produce a large increase in $\left[\mathrm{Fe}^{2+}\right]_{\mathrm{i}}$. These data unequivocally demonstrate that an elevation of intracellular $\mathrm{Fe}^{2+}$ is necessary for the expression of injury. Interestingly, in neurons, the effects of $\mathrm{Fe}^{2+}$ were significantly diminished by the simultaneous addition of DFO. However, astrocytes were resistant to $\mathrm{Fe}^{2+}$-mediated injury, although we used a substantially higher concentration of $\mathrm{Fe}^{2+}$ in these experiments (Fig. 6B). Oligodendrocytes appeared to be even more sensitive to $\mathrm{Fe}^{2+}$. mediated injury, although it was still necessary for the $\mathrm{Fe}^{2+}$ to enter the cells to produce injury (Fig. 6C). It is notable that we were unable to observe injury in astrocytes, although the elevation in $\left[\mathrm{Fe}^{2+}\right]_{\mathrm{i}}$ was similar in all three cell types.

\section{DISCUSSION}

In this study, we have adapted the use of the cation-sensitive dye fura- 2 for the detection of $\left[\mathrm{Fe}^{2+}\right]_{\mathrm{i}}$. We have been able to demonstrate that an ionophore, pyrithione, can rapidly increase $\left[\mathrm{Fe}^{2+}\right]_{\mathrm{i}}$ in primary cultures of neurons, astrocytes, and oligodendrocytes. We have also shown that cell-permeant iron chelators, such as bipyridyl and TPEN, can effectively decrease $\left[\mathrm{Fe}^{2+}\right]_{\mathrm{i}}$ in these cells, whereas the acute application of desferoxamine was not effective. Using this detection approach, we have been able to provide what we believe to be the first demonstration of the real-time detection of changes in the redox state of an intracellular cation by following the peroxide-induced oxidation of $\mathrm{Fe}^{2+}$ to $\mathrm{Fe}^{3+}$ and its spontaneous reduction. Finally, we have found that an elevation in $\left[\mathrm{Fe}^{2+}\right]_{i}$, but not extracellular $\mathrm{Fe}^{2+}$, is acutely toxic to neurons and oligodendrocytes but not astrocytes in culture. Iron is an important mediator of cellular injury in the brain, and these experiments will help establish both the characteristics of iron movement as well as the consequences of acute changes in $\left[\mathrm{Fe}^{2+}\right]_{\mathrm{i}}$.

It is generally believed that $\mathrm{Fe}^{3+}$ is transported into cells bound to transferrin, where it is subsequently stored in the form of $\mathrm{Fe}^{3+}$ bound to ferritin (Qian and Tang, 1995; Malecki et al., 1999; Wessling-Resnick, 1999). Although all cells in the nervous system require iron, oligodendrocytes appear to be particularly well equipped with iron transport capabilities, based on their expression of transferrin receptors (Connor et al., 1992; Connor, 1997). Other iron transport mechanisms have also been suggested, such as the recently described divalent cation transporter (Gunshin et al., 1997; Qian and Wang, 1998; Picard et al., 2000). The mechanisms for removing iron from cells are less well understood, but a recent study described an ATP-driven iron efflux pathway that is induced by iron (Baranano et al., 2000).

A number of detection methods have been used for monitoring iron movement in cells. Early studies established that ${ }^{55} \mathrm{Fe}$ could be used to track the accumulation of iron in both neurons and glia in culture (Swaiman and Machen, 1984, 1985; Hulet et al., 2000), as well as in vivo (Gocht et al., 1993; Crowe and Morgan, 1994). Several different fluorescence-based methods have also been used, although there is relatively little information from these methods using neural cells. Calcein and several forms of Phen Green have been successfully used in hepatocytes (Breuer et al., 1995b; Staubli and Boelsterli, 1998) and K562 cells (Breuer et al., 1995a) and have been quite useful for detecting the pool of chelatable iron (i.e., the cytoplasmic pool of iron that is not incorporated into proteins or bound to ferritin). Iron is detected by these dyes by fluorescence quenching, as observed here with fura-2, so it is reasonable to ask whether fura- 2 offers advantages over these previously used approaches.

Although calcein is a bright and stable dye, it has very high affinity for both $\mathrm{Fe}^{2+}$ and $\mathrm{Fe}^{3+}$ (affinity constants of $\sim 10^{-14}$ and 

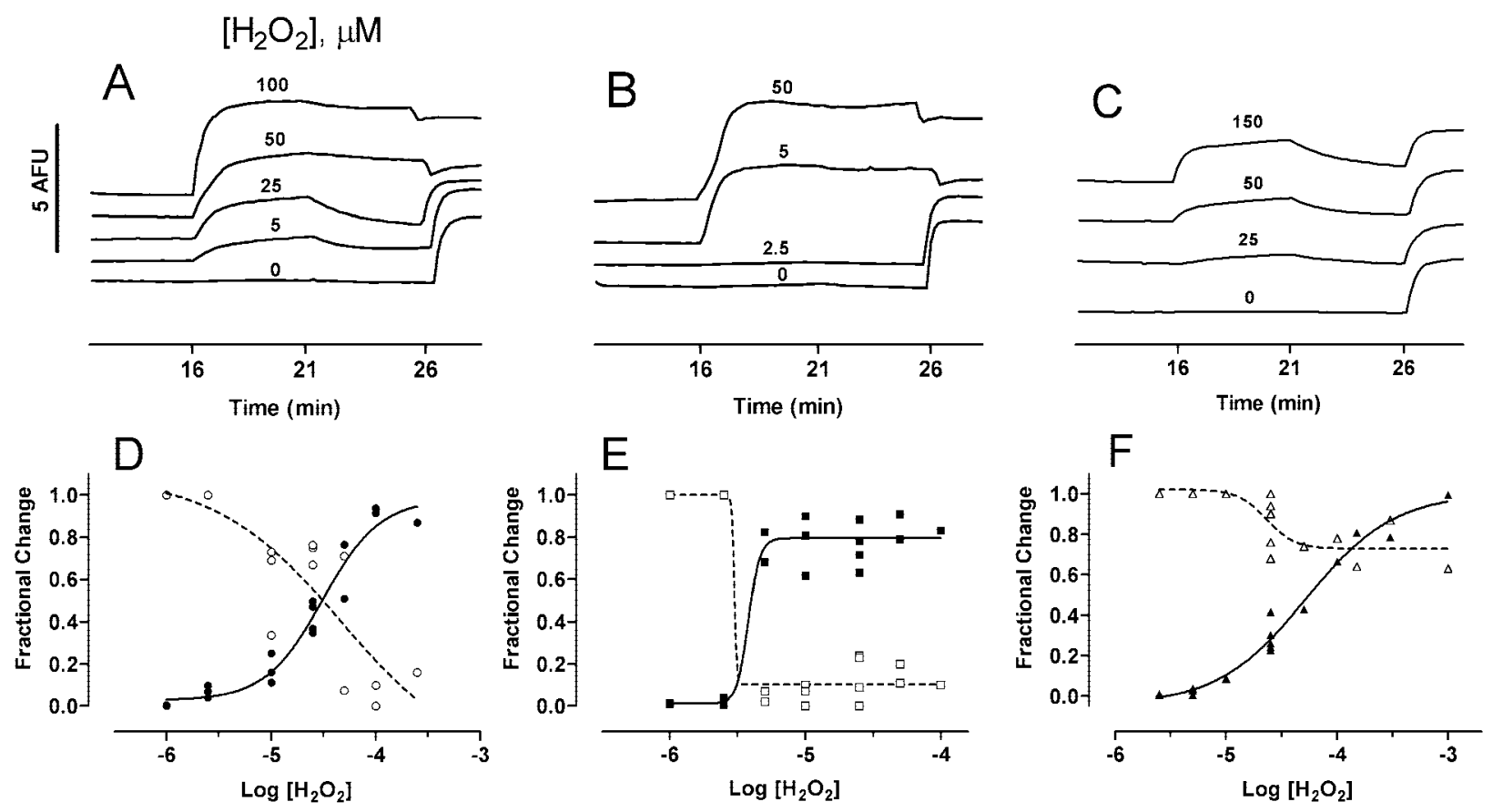

Figure 5. Oxidation modulation in neurons, astrocytes, and oligodendrocytes. Using the paradigm illustrated in Figure 4, the concentration dependence of the effects of $\mathrm{H}_{2} \mathrm{O}_{2}$ was determined. Neurons $(A)$, astrocytes $(B)$, and oligodendrocytes $(C)$ were $\mathrm{Fe}^{2+}$ loaded using $20 \mu \mathrm{M}$ Pyr/75 $\mu \mathrm{M}$ DFO/150 $\mu \mathrm{M}$ $\mathrm{Fe}^{2+}$ and were then exposed to various concentrations of $\mathrm{H}_{2} \mathrm{O}_{2}$ as indicated, allowed to recover, and chelated with $25 \mu \mathrm{M}$ TPEN. Each trace represents the mean signal from all of the cells in a single coverslip. Only one concentration of peroxide was used per coverslip. $A F U$, Arbitrary fluorescence units. The extent of reversal of the quenching was determined using the following equation: Fractional change $=\left(\beta_{375}-\alpha_{375}\right) /\left(\epsilon_{375}-\alpha_{375}\right)$, where the symbols represent the fluorescence intensity at the points indicated in Figure 4. These values were determined in neurons $(D)$, astrocytes $(E)$, and oligodendrocytes $\left(F\right.$; closed symbols). The $\mathrm{EC}_{50}$ for the effect of $\mathrm{H}_{2} \mathrm{O}_{2}$ on neurons, astrocytes, and oligodendrocytes was $30.9,3.8$, and $52 \mu \mathrm{M}$, respectively. The degree of recovery from oxidation was determined after $5 \mathrm{~min}$ of washout of the $\mathrm{H}_{2} \mathrm{O}_{2}$ stimuli and was also calculated for each cell type using the following equation: Fractional change $=\left(\beta_{375}-\delta_{375}\right) /\left(\beta_{375}-\alpha_{375}\right)$, where the symbols represent the fluorescence intensity at the points indicated in Figure 4. These values are shown using open symbols in the figures. The $\mathrm{EC}_{50}$ for the prevention of recovery after various $\left[\mathrm{H}_{2} \mathrm{O}_{2}\right]$ for neurons, astrocytes, and oligodendrocytes was $46.3,3$, and $23.2 \mu \mathrm{M}$, respectively. Each trace represents $\geq 18$ coverslips of that cell type from at least three culture dates. Solid and dashed lines on graphs $D-F$ represent calculated dose-response curves. Each symbol on graphs $D-F$ represents the mean value from a single coverslip.
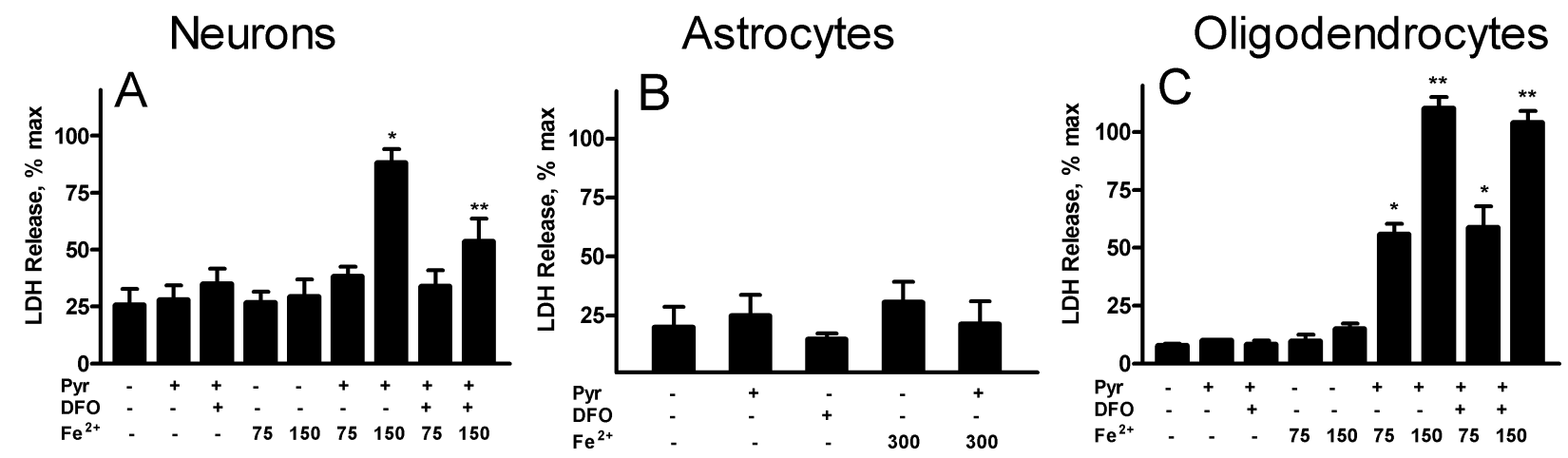

Figure 6. Intracellular $\mathrm{Fe}^{2+}$ causes neuron $(A)$ and oligodendrocyte $(C)$ but not astrocyte $(B)$ death. Cells were washed in TBSS and treated for 5 min with $20 \mu \mathrm{M}$ Pyr and $75 \mu \mathrm{M}$ DFO in the absence or presence of $\mathrm{Fe}^{2+}$ at the indicated concentration. LDH release was measured 8 hr after the stimulus. Results are a measure of the percentage of LDH release of an $8 \mathrm{hr}$ exposure of $10 \mu \mathrm{M}$ 4-bromo-A23187 (100\% death). These data represent the mean \pm SEM of at least four culture dates. Significant differences are indicated: $* p<0.05$ when the result was significantly different from controls and $* * p<$ 0.05 when the result was significantly different from treatment with $\mathrm{Fe}^{2+}$ alone.

$10^{-24} \mathrm{M}$, respectively). Although this has the advantage of profound sensitivity to iron, it would not make the critical distinction between the redox state of the free iron, and it may not be suitable for the range of $\left[\mathrm{Fe}^{2+}\right]_{\mathrm{i}}$ detected in this study. We have not yet been able to observe changes in $\left[\mathrm{Fe}^{2+}\right]_{\mathrm{i}}$ associated with physiological transport pathways. However, the toxicity experiments demonstrate that the elevation of $\left[\mathrm{Fe}^{2+}\right]_{i}$ observed in these ex- periments appears to be in the range necessary to kill cells, so fura-2 has the appropriate sensitivity for alterations in $\left[\mathrm{Fe}^{2+}\right]_{\mathrm{i}}$ in the toxic range. Calcein has also been reported to generate singlet oxygen on illumination (Beghetto et al., 2000) and may also load into subcellular compartments (Rauen et al., 2000), which is not necessarily optimal for imaging experiments. Studies suggest that Phen Green SK is insensitive to calcium and zinc but also does 
not make the distinction between $\mathrm{Fe}^{2+}$ and $\mathrm{Fe}^{3+}$ very effectively (Petrat et al., 1999). Fura-2 is widely used as a calcium-sensitive dye, and both the calcium and the zinc sensitivity of this dye could make iron detection difficult. However, we have demonstrated here that there are clear spectral differences, both in vitro and in cells, that allow the distinction between alterations in $\left[\mathrm{Ca}^{2+}\right]_{\mathrm{i}}$, $\left[\mathrm{Zn}^{2+}\right]_{\mathrm{i}}$, and $\left[\mathrm{Fe}^{2+}\right]_{\mathrm{i}}$. We have also established that the fluorescence signals that we report here depend on the presence of the cation of interest in the extracellular buffer and are reversed by heavy-metal chelators. Thus, although the fura- 2 signal in unstimulated cells certainly reflects the resting $\left[\mathrm{Ca}^{2+}\right]_{i}$, alterations in the fluorescence signal after exposure to pyrithione and $\mathrm{Fe}^{2+}$ are probably reporting $\left[\mathrm{Fe}^{2+}\right]_{\mathrm{i}}$. However, these experiments also establish the concept that dyes such as fura-2 can report changes in many different ionic species within cells (e.g., including zinc) (Cheng and Reynolds, 1998; Aizenman et al., 2000).

The ability to detect acute increases in $\left[\mathrm{Fe}^{2+}\right]_{\mathrm{i}}$ in cultured cells provided the opportunity to monitor several other parameters of interest; e.g., we were able to compare the effectiveness of iron chelators in reversing increases in $\left[\mathrm{Fe}^{2+}\right]_{\mathrm{i}}$. As has been reported previously (Cabantchik et al., 1996; Zanninelli et al., 1997), the iron chelator desferroxamine is not at all effective at acutely altering intracellular iron, despite its widespread use for this purpose. In contrast, bipyridyl and TPEN effectively reversed the increase in $\left[\mathrm{Fe}^{2+}\right]_{i}$, consistent with their ability to rapidly penetrate cells. In this study, we were also able to monitor alterations in the redox state of iron, because of the differential sensitivity of fura- 2 to $\mathrm{Fe}^{2+}$ compared with $\mathrm{Fe}^{3+}$. It is generally believed that the limited amount of chelatable iron in cells is in the reduced state. This is the form that binds most effectively to fura- 2 and is also the species that can contribute to oxidant production via the Fenton reaction. However, conversion from $\mathrm{Fe}^{2+}$ to $\mathrm{Fe}^{3+}$ should occur readily if the reducing environment of the cell changes. We were effectively able to accomplish this by exposing cells to $\mathrm{H}_{2} \mathrm{O}_{2}$. This resulted in the reversal of the $\mathrm{Fe}^{2+}$, reflecting the lower affinity of fura- 2 for $\mathrm{Fe}^{3+}$. Interestingly, cells could recover from low concentrations of peroxide spontaneously, whereas exposure to higher concentrations $(\sim 100 \mu \mathrm{M}$ or more) resulted in an irreversible dequenching effect. This may imply that the antioxidant defenses of the cells were overcome at this point so that the predominant environment of the cell became oxidizing rather than reducing. Thus, if detection of $\left[\mathrm{Fe}^{2+}\right]_{\mathrm{i}}$ is possible, it might also provide a reasonable surrogate for the real-time measurement of the cellular redox status.

In general, the ionophore-mediated changes in the fura- 2 signal were quite similar between cells, which suggests that neurons, astrocytes, and oligodendrocytes were loaded with iron equally. It is surprising, then, that astrocytes appeared to be completely resistant to iron-induced injury. This is also unexpected in view of the greater sensitivity of astrocytes to peroxide-induced changes in the cellular redox state. We do not have an explanation for this differential sensitivity. We have noted previously that astrocytes are less sensitive than neurons to the neurotoxic effects of increased $\left[\mathrm{Zn}^{2+}\right]_{\mathrm{i}}$ (Dineley et al., 2000), and the combined observations of resistance to metals might be consistent with differential expression of metal-binding proteins, such as metallothionein in astrocytes compared with neurons (Aschner, 1996). However, we do not have any data that directly address this possibility.

The methods used here were valuable in detecting changes in $\left[\mathrm{Fe}^{2+}\right]_{\mathrm{i}}$ in response to acute stimuli and for setting up acute injury to cells. The extent to which this models disease in vivo is less clear. Obviously, a few minutes of exposure to elevated $\left[\mathrm{Fe}^{2+}\right]_{\mathrm{i}}$ will not effectively mimic chronic neurodegenerative disease states such as Parkinson's disease, where the disordered iron metabolism may extend over several decades. However, more acute iron exposure might occur in response to more rapid pathophysiological stimuli (e.g., the acidosis that accompanies cerebral ischemia might be expected to mobilize iron more rapidly) (Bralet et al., 1992; Winterbourn, 1995; Dorrepaal et al., 1996). The oxidant-mediated release of iron from enzymes (such as aconitase) that have labile [4Fe-4S] centers might also occur more rapidly (Gardner, 1997). Notably, in these cases, the elevation of iron would be intracellular, where our data show that it will be substantially more toxic. It is widely appreciated that hemorrhagic stroke is more injurious than the ischemic form, and this might also be associated with the acute mobilization of iron from hemoglobin. However, in this scenario, a mechanism for the transport of iron into cells is necessary for the expression of iron-mediated injury. Nevertheless, the methods and results reported here should facilitate future studies on cellular handling of iron.

\section{REFERENCES}

Aisen P (1994) The transferrin receptor and the release of iron from transferrin. Adv Exp Med Biol 356:31-40.

Aizenman E, Stout AK, Hartnett KA, Dineley KE, McLaughlin BA, Reynolds IJ (2000) Induction of neuronal apoptosis by thiol oxidation: putative role of intracellular zinc release. J Neurochem 75:1878-1888.

Aschner M (1996) The functional significance of brain metallothioneins. FASEB J 10:1129-1136.

Baranano DE, Wolosker H, Bae BI, Barrow RK, Snyder SH, Ferris CD (2000) A mammalian iron ATPase induced by iron. J Biol Chem 275:15166-15173.

Beghetto C, Renken C, Eriksson O, Jori G, Bernardi P, Ricchelli F (2000) Implications of the generation of reactive oxygen species by photoactivated calcein for mitochondrial studies. Eur J Biochem 267:5585-5592.

Bralet J, Schreiber L, Bouvier C (1992) Effect of acidosis and anoxia on iron delocalization from brain homogenates. Biochem Pharmacol 43:979-983.

Breuer W, Epsztejn S, Cabantchik ZI (1995a) Iron acquired from transferrin by K562 cells is delivered into a cytoplasmic pool of chelatable iron(II). J Biol Chem 270:24209-24215.

Breuer W, Epsztejn S, Millgram P, Cabantchik IZ (1995b) Transport of iron and other transition metals into cells as revealed by a fluorescent probe. Am J Physiol 268:C1354-C1361.

Brocard JB, Tassetto M, Reynolds IJ (2001) Quantitative evaluation of mitochondrial calcium content following glutamate receptor stimulation in rat cortical neurones. J Physiol (Lond) 531:793-805.

Cabantchik ZI, Glickstein H, Milgram P, Breuer W (1996) A fluorescence assay for assessing chelation of intracellular iron in a membrane model system and in mammalian cells. Anal Biochem 233:221-227.

Castellani RJ, Siedlak SL, Perry G, Smith MA (2000) Sequestration of iron by Lewy bodies in Parkinson's disease. Acta Neuropathol 100:111-114.

Cheng C, Reynolds IJ (1998) Calcium-sensitive fluorescent dyes can report increases in intracellular free zinc concentration in cultured forebrain neurons. J Neurochem 71:2401-2410.

Connor JR (1997) Metals and oxidative damage in neurological disorders. New York: Plenum.

Connor JR, Menzies SL, St Martin SM, Mufson EJ (1992) A histochemical study of iron, transferrin, and ferritin in Alzheimer's diseased brains. J Neurosci Res 31:75-83.

Crowe A, Morgan EH (1994) Effects of chelators on iron uptake and release by the brain in the rat. Neurochem Res 19:71-76.

Deibel MA, Ehmann WD, Markesbery WR (1996) Copper, iron, and zinc imbalances in severely degenerated brain regions in Alzheimer's disease: possible relation to oxidative stress. J Neurol Sci 143:137-142.

Dexter DT, Wells FR, Lees AJ, Agid F, Agid Y, Jenner P, Marsden CD (1989) Increased nigral iron content and alterations in other metal ions occurring in brain in Parkinson's disease. J Neurochem 52:1830-1836.

Dineley KE, Scanlon JM, Kress GJ, Stout AK, Reynolds IJ (2000) Astrocytes are more resistant than neurons to the cytotoxic effects of increased $\left[\mathrm{Zn}^{2+}\right]_{\text {i. }}$ Neurobiol Dis 7:310-320.

Dorrepaal CA, Berger HM, Benders MJ, Zoeren-Grobben D, Van de Bor M, Van Bel F (1996) Nonprotein-bound iron in postasphyxial reperfusion injury of the newborn. Pediatrics 98:883-889. 
Gardner PR (1997) Superoxide-driven aconitase Fe-S center cycling. Biosci Rep 17:33-42.

Gerlach M, Ben-Shachar D, Riederer P, Youdim MBH (1994) Altered brain metabolism of iron as a cause of neurodegenerative diseases. J Neurochem 63:793-807.

Gocht A, Keith AB, Candy JM, Morris CM (1993) Iron uptake in the brain of the myelin-deficient rat. Neurosci Lett 154:187-190.

Golub MS, Han B, Keen CL (1996) Aluminum alters iron and manganese uptake and regulation of surface transferrin receptors in primary rat oligodendrocyte cultures. Brain Res 719:72-77.

Good PF, Perl DP, Bierer LM, Schmeidler J (1992) Selective accumulation of aluminum and iron in the neurofibrillary tangles of Alzheimer's disease: a laser microprobe (LAMMA) study. Ann Neurol 31:286-292.

Grynkiewicz G, Poenie M, Tsien RY (1985) A new generation of $\mathrm{Ca}^{2+}$ indicators with greatly improved fluorescence properties. J Biol Chem 260:3440-3450.

Gunshin H, Mackenzie B, Berger UV, Gunshin Y, Romero MF, Boron WF, Nussberger S, Gollan JL, Hediger MA (1997) Cloning and characterization of a mammalian proton-coupled metal-ion transporter. Nature 388:482-488.

Hulet SW, Heyliger SO, Powers S, Connor JR (2000) Oligodendrocyte progenitor cells internalize ferritin via clathrin-dependent receptor mediated endocytosis. J Neurosci Res 61:52-60.

Jellinger KA (1999) The role of iron in neurodegeneration: prospects for pharmacotherapy of Parkinson's disease. Drugs Aging 14:115-140.

Kienzl E, Jellinger K, Stachelberger H, Linert W (1999) Iron as catalyst for oxidative stress in the pathogenesis of Parkinson's disease? Life Sci 65:1973-1976.

Kress G, Dineley KE, Reynolds IJ (2000) Intracellular $\mathrm{Fe}^{2+}$ fluorescence measurements and intracellular $\mathrm{Fe}^{2+}$ induced neurotoxicity. Soc Neurosci Abstr 26:2071.

Lauffer RB (1992) Iron and human disease. Boca Raton, FL: CRC.

LeVine SM (1997) Iron deposits in multiple sclerosis and Alzheimer's disease brains. Brain Res 760:298-303.

Lipscomb DC, Gorman LG, Traystman RJ, Hurn PD (1998) Low molecular weight iron in cerebral ischemic acidosis in vivo. Stroke 29:487-492.

Malecki EA, Devenyi AG, Beard JL, Connor JR (1999) Existing and emerging mechanisms for transport of iron and manganese to the brain. J Neurosci Res 56:113-122.

McCarthy KD, de Vellis J (1980) Preparation of separate astroglial and oligodendroglial cell cultures from rat cerebral tissue. J Cell Biol 85:890-902.

Petrat F, Rauen U, De Groot H (1999) Determination of the chelatable iron pool of isolated rat hepatocytes by digital fluorescence microscopy using the fluorescent probe, phen green SK. Hepatology 29:1171-1179.

Picard V, Govoni G, Jabado N, Gros P (2000) Nramp 2 (DCT1/DMT1) expressed at the plasma membrane transports iron and other divalent cations into a calcein-accessible cytoplasmic pool. J Biol Chem 275:35738-35745.
Qian ZM, Tang PL (1995) Mechanisms of iron uptake by mammalian cells. Biochim Biophys Acta 1269:205-214.

Qian ZM, Wang Q (1998) Expression of iron transport proteins and excessive iron accumulation in the brain in neurodegenerative disorders. Brain Res Brain Res Rev 27:257-267.

Rauen U, Petrat F, Li T, De Groot H (2000) Hypothermia injury/coldinduced apoptosis-evidence of an increase in chelatable iron causing oxidative injury in spite of low $\mathrm{O} 2-/ \mathrm{H} 2 \mathrm{O} 2$ formation. FASEB J 14:1953-1964.

Reif DW (1992) Ferritin as a source of iron for oxidative damage. Free Radic Biol Med 12:417-427.

Schapira AH (1999) Mitochondrial involvement in Parkinson's disease, Huntington's disease, hereditary spastic paraplegia and Friedreich's ataxia. Biochim Biophys Acta 1410:159-170.

Smith MA, Nunomura A, Zhu X, Takeda A, Perry G (2000) Metabolic, metallic, and mitotic sources of oxidative stress in Alzheimer disease. Antioxid Redox Signal 2:413-420.

Sofic E, Riederer P, Heinsen H, Beckmann H, Reynolds GP, Hebenstreit G, Youdim MB (1988) Increased iron (III) and total iron content in post mortem substantia nigra of parkinsonian brain. J Neural Transm 74:199-205.

Staubli A, Boelsterli UA (1998) The labile iron pool in hepatocytes: prooxidant-induced increase in free iron precedes oxidative cell injury. Am J Physiol 274:G1031-G1037.

Swaiman KF, Machen VL (1984) Iron uptake by mammalian cortical neurons. Ann Neurol 16:66-70.

Swaiman KF, Machen VL (1985) Iron uptake by glial cells. Neurochem Res 10:1635-1644.

Thompson KJ, Shoham S, Connor JR (2001) Iron and neurodegenerative disorders. Brain Res Bull 55:155-164.

Tsien RY (1999) Monitoring cell calcium. In: Calcium as a cellular regulator (Carafoli E, Klee CB, eds), pp 28-54. New York: Oxford UP.

Votyakova TV, Reynolds IJ (2001) $\Delta \psi$ m-dependent and independent production of reactive oxygen species by brain mitochondria. J Neurochem 79:266-277.

Waldvogel D, van Gelderen P, Hallett M (1999) Increased iron in the dentate nucleus of patients with Friedrich's ataxia. Ann Neurol 46:123-125.

Wardman P, Candeias LP (1996) Fenton chemistry: an introduction. Radiat Res 145:523-531.

Wessling-Resnick M (1999) Biochemistry of iron uptake. Crit Rev Biochem Mol Biol 34:285-314.

Winterbourn CC (1995) Toxicity of iron and hydrogen peroxide: the Fenton reaction. Toxicol Lett 82-83:969-974.

Youdim MB, Ben Shachar D, Yehuda S, Riederer P (1990) The role of iron in the basal ganglion. Adv Neurol 53:155-162.

Zanninelli G, Glickstein H, Breuer W, Milgram P, Brissot P, Hider RC, Konijn AM, Libman J, Shanzer A, Cabantchik ZI (1997) Chelation and mobilization of cellular iron by different classes of chelators. Mol Pharmacol 51:842-852. 